\title{
In Vitro Anti-Inflammatory, Anticancer (MCF-7, 3T3, and HeLa Cell Lines), and Brine Shrimp Lethality Assay and FTIR Analysis of the Extract and Fractions of the Whole Plant of Heliotropium europaeum
}

\author{
Jahangir Khan Achakzai $\left(\mathbb{D},{ }^{1}\right.$ Muhammad Anwar Panezai ${ }^{10},{ }^{1}$ Basira Akhtar, \\ Shahabuddin Kakar, ${ }^{3}$ Ali Akbar ${ }^{D},{ }^{4}$ Abdul Manan Kakar, ${ }^{1}$ Javed Khan, ${ }^{5}$ \\ Nazima Yousaf Khan, ${ }^{1}$ Ghulam Mustafa Khan, ${ }^{6}$ Muhammad Imran, ${ }^{1}$ Marina Panezai, \\ Nisar Ahmed Shahwani, ${ }^{7}$ and Tehmina Achakzai ${ }^{7}$ \\ ${ }^{1}$ Institute of Biochemistry, University of Balochistan, Quetta 87300, Pakistan \\ ${ }^{2}$ Department of Botany, University of Balochistan, Quetta 87300, Pakistan \\ ${ }^{3}$ Department of Zoology, University of Balochistan, Quetta 87300, Pakistan \\ ${ }^{4}$ Department of Microbiology, University of Balochistan, Quetta 87300, Pakistan \\ ${ }^{5}$ Department of Microbiology, Quaid-i-Azam University, Islamabad 45320, Pakistan \\ ${ }^{6}$ Department of Chemistry, University of Balochistan, Quetta 87300, Pakistan \\ ${ }^{7}$ Faculty of Pharmacy, University of Balochistan, Quetta 87300, Pakistan
}

Correspondence should be addressed to Muhammad Anwar Panezai; anwarpanezai@yahoo.com

Received 10 August 2019; Accepted 7 January 2020; Published 1 February 2020

Academic Editor: Carla Pagliari

Copyright ( 2020 Jahangir Khan Achakzai et al. This is an open access article distributed under the Creative Commons Attribution License, which permits unrestricted use, distribution, and reproduction in any medium, provided the original work is properly cited.

In this study, anti-inflammatory, anticancer, brine shrimp lethality, and FTIR studies were evaluated. The oxidative burst assay using the chemiluminescence technique, MTT assay, brine shrimp lethality assay, and FTIR analysis were the methods used for the evaluation of anti-inflammatory, anticancer, brine shrimp lethality, and FTIR studies, respectively. The whole-plant butanol fraction of Heliotropium europaeum (WBFHE) showed anti-inflammatory activity on ROS having $\mathrm{IC}_{50} 14.7 \pm 2.5$ while the extract and other fractions of the whole plant of Heliotropium europaeum exhibited no anti-inflammatory activity. None of the extract and fractions of the whole plant of Heliotropium europaeum exhibited anticancer (MCF-7, 3T3, and HeLa cell lines) activities. The whole-plant aqueous fraction of Heliotropium europaeum (WAFHE) and whole-plant butanol fraction of Heliotropium europaeum (WBFHE) showed lethality at high concentration while at low concentration, no toxicity was shown. The whole-plant methanolic extract of Heliotropium europaeum (WMEHE) and whole-plant n-hexane fraction of Heliotropium europaeum (WHFHE) exhibited no toxicity. FTIR interpretation showed the functional groups for the aromatic compounds, phenols, carboxylic acids, esters, alkanes, alkenes, alcohols, alkyl halides, sulfate esters, phosphines, silanes, nitriles, thiols, amines, phosphoric acids, and nitro compounds.

\section{Introduction}

With the beginning of folk medicine, the usage of medicinal plants and their incorporation into allopathic and traditional medicine have a long history [1]. Medicinal plants have effec- tive pharmacological activities due to the presence of secondary metabolites such as alkaloids, saponins, tannins, terpenoids, flavoids, inulin, glycosides, steroids, phlobatannins, terpenoids, phenols, and naphthoquinone. These phytochemicals have less toxicity and side effects [2-5]. The 
medicinal plant Heliotropium europaeum belongs to the Boraginaceae family, grown in summer, and is a heliotrope [6]. This toxic and medicinal plant is distributed in Middle Eastern countries, for instance, Saudi Arabia, Iraq, Syria, Iran, and Egypt, and Mediterranean countries, for instance, Turkey, Spain, Greece, France, Bosnia, Italy, Albania, Monaco, and Croatia, and is introduced accidently in Australia [7, 8]. Heliotropium europaeum has a poisonous and therapeutic effect, comprises pyrrolizidine which is an important alkaloid, and shows therapeutic properties such as antitumor, insecticidal, hepatotoxic, antibacterial, antifungal, mutagenic, teratogenic, mydriatic, and antispasmodic [9-11]. In this research study, the antiinflammatory, anticancer (MCF-7, 3T3, and HeLa cell lines), and brine shrimp lethality assay and FTIR studies of the extract and fractions of the whole plant of Heliotropium europaeum are examined.

\section{Materials and Methods}

2.1. Plant Materials. The plant material (whole plant) of Heliotropium europaeum was collected from Dera Bugti, Balochistan, Pakistan, and identified by Prof. Dr. Rasool Bakhsh Tareen and Dr. Shazia Saeed, Department of Botany, University of Balochistan, Quetta, Pakistan, and was deposited in the Herbarium, Department of Botany, University of Balochistan, Quetta, Pakistan, with voucher number QUETTA000016.

2.2. Extraction of the Plant Material (Whole Plant) of Heliotropium europaeum. The whole plant of Heliotropium europaeum was washed with tap water and then rinsed with distilled water in order to reduce contamination which occurred during transportation and handling and shade dried for one month. This is due to the radiation from sunlight that destroys bioactive compounds present in the whole plant of Heliotropium europaeum. The dried whole plant was grinded in a mechanical grinder, and then, $12 \mathrm{~kg}$ powdered plant material was soaked in 20 litres of methanol, kept for 7 days, and shaken daily. After a 7-day period, the methanol-containing whole plant of Heliotropium europaeum was filtered with Whatman filter paper No. 1 and concentrated under reduced pressure at temperature below $55^{\circ} \mathrm{C}$ in a rotary evaporator. The dried semisolid whole-plant methanolic extract of Heliotropium europaeum (WMEHE) was $288 \mathrm{~g}$. This crude extract $10 \mathrm{~g}$ was examined for biological activities such as anti-inflammatory, brine shrimp lethality assay, and anticancer MCF-7 cell line, anticancer 3T3 cell line, and anticancer HeLa cell line activities and FTIR analysis while the remaining extract was fractionated with solvents, for instance, n-hexane, aqueous solution, butanol, ether, dichloromethane, chloroform, and tetrachloromethane $[12,13]$.

2.3. Fractionation of the Crude Extract. The crude extract was fractionated with solvents such as n-hexane, aqueous solution, butanol, ether, dichloromethane, chloroform, and tetrachloromethane to form the whole-plant $n$-hexane fraction of Heliotropium europaeum (WHFHE) $3 \mathrm{~g}$, wholeplant aqueous fraction of Heliotropium europaeum (WAFRR) $121.8 \mathrm{~g}$, whole-plant butanol fraction of Heliotropium europaeum (WBFHE) $26 \mathrm{~g}$, whole-plant ether fraction of Heliotropium europaeum (WEFHE) $0.2 \mathrm{~g}$, whole-plant dichloromethane fraction of Heliotropium europaeum (WDFHE) $0.1 \mathrm{~g}$, whole-plant chloroform fraction of Heliotropium europaeum (WCFHE) $0.3 \mathrm{~g}$, and whole-plant tetrachloromethane fraction of Heliotropium europaeum (WTFHE) $0.1 \mathrm{~g}$. The whole-plant $\mathrm{n}$-hexane fraction of Heliotropium europaeum (WHFHE), whole-plant aqueous fraction of Heliotropium europaeum (WAFRR), and wholeplant butanol fraction of Heliotropium europaeum (WBFHE) were examined for anticancer, anti-inflammatory, and brine shrimp lethality assay and FTIT analysis while the wholeplant ether fraction of Heliotropium europaeum (WEFHE), whole-plant dichloromethane fraction of Heliotropium europaeum (WDFHE), whole-plant chloroform fraction of Heliotropium europaeum (WCFHE), and whole-plant tetrachloromethane fraction of Heliotropium europaeum (WTFHE) were examined for FTIR analysis $[12,13]$.

2.4. Anti-Inflammatory Assay. For the anti-inflammatory assay, the oxidative burst assay using the chemiluminescence technique was used.

2.5. Oxidative Burst Assay Using the Chemiluminescence Technique. In this technique, $25 \mu \mathrm{l}$ diluted whole blood in $\mathrm{HBSS}^{++}$containing magnesium chloride and calcium chloride (Sigma, St. Louis, USA) and $25 \mu \mathrm{l}$ of the extract and fractions of medicinal plants were incubated for $15 \mathrm{~min}$ at $37^{\circ} \mathrm{C}$ in the thermostat chamber of a luminometer (Labsystems, Helsinki, Finland) and then plated in 96-well plates (Costar, NY, USA). Control wells contain $\mathrm{HBSS}^{++}$ and cells while blank wells contain $\mathrm{HBSS}^{++} .25 \mu$ l luminol (Sigma Chemical Co., St. Louis, MO, USA) and $25 \mu \mathrm{l}$ serum opsonized zymosan (Sigma Chemical Co., St. Louis, MO, USA) were added into each well. In terms of relative light units, the level of ROS was recorded in a luminometer. In this assay, ibuprofen with $\mathrm{IC}_{50} 11.2 \pm 1.9$ is used as a standard drug [14].

2.6. MTT Assay (MCF-7 Cell Lines, 3 T3 Cell Lines, and HeLa Cell Lines). The MCF cell line, 3T3 cell line, and HeLa cell line were purchased from the American Type Culture Collection (ATCC). In this assay, Dulbecco's modified Eagle's medium containing ten percent fetal bovine serum and two percent antibiotics such as streptomycin with $100 \mu \mathrm{g} / \mathrm{ml}$ and penicillin with $100 \mathrm{IU} / \mathrm{ml}$ was used for culturing MCF7 cell lines, 3T3 cell lines, and HeLa cell lines which were then kept in five percent $\mathrm{CO}_{2}$ and incubated at $37^{\circ} \mathrm{C}$. MCF-7 cells, 3T3 cells, and HeLa cells were harvested when confluency was developed and $5 \times 10^{4}$ cells per well were plated in a 96-well flat. After 24 hours, the extract and fractions of medicinal plants with $50 \mu \mathrm{g} / \mathrm{ml}$ were added and then incubated for 48 hours. After incubation, the extract/fractions were removed. To each well, $100 \mu \mathrm{l}$ with concentration of $0.5 \mathrm{mg} / \mathrm{ml}$ MTT was added and kept in an incubator for 4 hours at $37^{\circ} \mathrm{C}$. MTT was reduced into formazan crystals 
TABle 1: Plant material (gm), yield (gm), and percentage yield of the extract and fractions of the whole plant of Heliotropium europaeum.

\begin{tabular}{|c|c|c|c|c|c|}
\hline Plant & Extract and fractions & Plant material & Plant material (gm) & Yield (gm) & $\begin{array}{c}\text { Percentage yield } \\
\% \text { Yield }=(\mathrm{W} 1 / \mathrm{W} 2) \times 100 \\
\text { W1 }=\text { yield }(\mathrm{gm}) \\
\mathrm{W} 2=\text { plant material }(\mathrm{gm})\end{array}$ \\
\hline \multirow{8}{*}{ Heliotropium europaeum } & WMEHE & Whole plant & 12000 & 288 & $2.4 \%$ \\
\hline & WHFHE & Whole plant & 12000 & 3 & $0.025 \%$ \\
\hline & WAFHE & Whole plant & 12000 & 121.8 & $1 \%$ \\
\hline & WBFHE & Whole plant & 12000 & 26 & $0.2 \%$ \\
\hline & WEFHE & Whole plant & 12000 & 0.2 & $0.0016 \%$ \\
\hline & WDFHE & Whole plant & 12000 & 0.1 & $0.0008 \%$ \\
\hline & WCFHE & Whole plant & 12000 & 0.3 & $0.0025 \%$ \\
\hline & WTFHE & Whole plant & 12000 & 0.1 & $0.0008 \%$ \\
\hline
\end{tabular}

which were then dissolved in $100 \mu \mathrm{l}$ DMSO and was taken at $570 \mathrm{~nm}$ absorbance using a microplate reader (SpectraMax Plus, Molecular Devices, CA, USA). In this assay, doxorubicin was used as a standard drug for the MCF-7 cell line and
HeLa cell line while cycloheximide was used as a standard drug for the $3 \mathrm{~T} 3$ cell line. The decrease in viable cells or percent inhibition was calculated with the help of the following formula:

$$
\text { \%inhibition }=100-\left(\frac{\text { mean of O.D.of test compound }- \text { mean of O.D.of negative control }}{\text { mean of O.D.of positive control }- \text { mean of O.D.of negative control }} \times 100\right) .
$$

For the calculation of $\mathrm{IC}_{50} 20 \mathrm{mM}$ stock solution of the extract/fractions, diluted into working solution with $50 \mu \mathrm{M}$, and then in order to get less than 50 percent inhibition, working solution is further diluted in serial dilutions. With the help of EZ-Fit5 software, $\mathrm{IC}_{50}$ is calculated [15].

2.7. Brine Shrimp Lethality Assay. B-Hatching techniques were used for the evaluation of toxicity.

2.8. B-Hatching Techniques. In this B-Hatching technique, scatter $50 \mathrm{mg}$ of brine shrimp eggs in a hatching tray which was already half filled with filtered brine solution. Put it in an incubator at $37^{\circ} \mathrm{C}$ for 2 days. Take $20 \mathrm{mg}$ of the extract and fractions of medicinal plants, and dissolve it in $2 \mathrm{ml}$ of solvent such as methanol. Transfer 5, 50, and $500 \mu \mathrm{l}$ from this solution to 3 vials, and bring the concentration to 10,100 , and $1000 \mu \mathrm{g} / \mathrm{ml}$. Overnight, allow the solvent to evaporate. With the help of a Pasteur pipette, put 30 larvae per vial. Add $5 \mathrm{ml}$ seawater. Under illumination, for 24 hours, incubate it at $25-27^{\circ} \mathrm{C}$. For positive and negative controls, add a reference cytotoxic drug along with solvent in other vials. Etoposide was the standard drug used in this research study with $7.4625 \mu \mathrm{g} / \mathrm{ml}$. For the determination of $\mathrm{LD}_{50}$, the Finney computer program was used [16].

2.9. FTIR Analysis. The extract and fractions of the plant were dried for the analysis of FTIR. In FTIR analysis, the extract and fractions of the plant with the concentration of $10 \mathrm{mg}$ were encapsulated in the pellet of $100 \mathrm{mg}$ of $\mathrm{KBr}$, for the preparation of the disc of the translucent sample which was then loaded in the FTIR spectroscope (Shimadzu, IRAffinity-1, Japan) [17].

\section{Results}

One extract and seven fractions were extracted and fractionated, respectively, from the whole plant of Heliotropium europaeum. Plant material (gm), yield (gm), and percentage yield of the extract and fractions of the whole plant of Heliotropium europaeum are shown in Table 1.

(1) Whole-plant methanolic extract of Heliotropium europaeum (WMEHE)

(2) Whole-plant n-hexane fraction of Heliotropium europaeum (WHFHE)

(3) Whole-plant aqueous fraction of Heliotropium europaeum (WAFHE)

(4) Whole-plant butanol fraction of Heliotropium europaeum (WBFHE)

(5) Whole-plant ether fraction of Heliotropium europaeum (WEFHE)

(6) Whole-plant dichloromethane fraction of Heliotropium europaeum (WDFHE) 
TABLE 2: Anti-inflammatory activities of the extract and fractions of the whole plant of Heliotropium europaeum.

\begin{tabular}{lcccc}
\hline S. no. & Extract/fraction/Std. drug & Conc. $(\mu \mathrm{g} / \mathrm{ml})$ & \% inhibition/stimulation & $\mathrm{IC}_{50} \pm$ S.D. \\
\hline 1 & WMEHE & 25 & 33.2 & - \\
2 & WHFHE & $250,50,10$ & - & $>250$ \\
3 & WAFHE & $250,50,10$ & - & $14.7 \pm 2.5$ \\
4 & WBFHE & $250,50,10$ & 73.2 & $11.2 \pm 1.9 \mu \mathrm{g} / \mathrm{ml}$ \\
5 & Ibuprofen & & - & -250 \\
\hline
\end{tabular}

TABLE 3: Anticancer assay (MCF-7) of the extract and fractions of the whole plant of Heliotropium europaeum.

\begin{tabular}{lcccrc}
\hline S. no. & Extract/fraction/Std. drug & Conc. $(\mu \mathrm{g} / \mathrm{ml})$ & \% inhibition/stimulation & \% viability & IC $_{50} \pm$ S.D. \\
\hline 1 & WMEHE & 50 & 10.38 & 89.62 & Inactive \\
2 & WHFHE & 50 & 20.89 & 79.11 & Inactive \\
3 & WAFHE & 50 & 29.19 & 70.81 & Inactive \\
4 & WBFHE & & 19.96 & 80.04 & Inactive \\
5 & Doxorubicin & 50 & 73.23 & 26.77 & $0.80 \pm 0.05$ \\
\hline
\end{tabular}

TABle 4: Anticancer assay (3T3) of the extract and fractions of the whole plant of Heliotropium europaeum.

\begin{tabular}{|c|c|c|c|c|c|}
\hline S. no. & Extract/fraction/Std. drug & Conc. $(\mu \mathrm{g} / \mathrm{ml})$ & $\%$ inhibition/stimulation & $\%$ viability & $\mathrm{IC}_{50} \pm$ S.D. \\
\hline 1 & WMEHE & 30 & 12 & 88 & Inactive \\
\hline 2 & WHFHE & 30 & 5 & 95 & Inactive \\
\hline 3 & WAFHE & 30 & 0 & 100 & Inactive \\
\hline 4 & WBFHE & & 11 & 89 & Inactive \\
\hline 5 & Cycloheximide & 30 & 71 & 29 & $0.85 \pm 0.07$ \\
\hline
\end{tabular}

TABle 5: Anticancer assay (HeLa cell line) of the extract and fractions of the whole plant of Heliotropium europaeum.

\begin{tabular}{lccccc}
\hline S. no. & Extract/fraction/Std. drug & Conc. $(\mu \mathrm{g} / \mathrm{ml})$ & $\%$ inhibition/stimulation & \% viability & IC $_{50} \pm$ S.D. \\
\hline 1 & WMEHE & 30 & 12 & 88 & Inactive \\
2 & WHFHE & 30 & 22 & Inactive \\
3 & WAFHE & 30 & 3 & 97 & Inactive \\
4 & WBFHE & 30 & 26 & 74 & Inactive \\
5 & Doxorubicin & 30 & 70 & 30 & $1.2 \pm 0.4$ \\
\hline
\end{tabular}

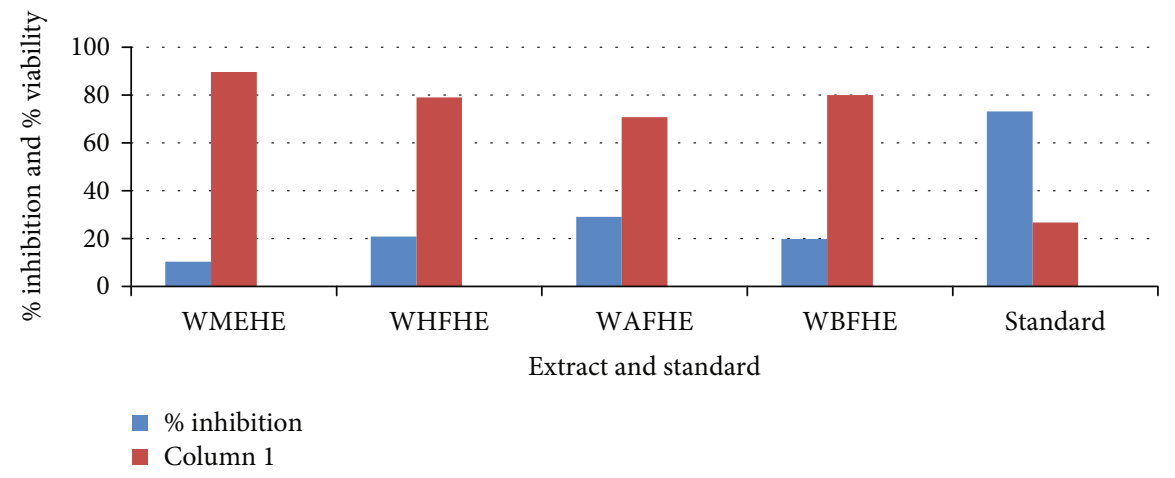

FIgURE 1: Anticancer assay (MCF-7) of the extract and fractions of the whole plant of Heliotropium europaeum. 


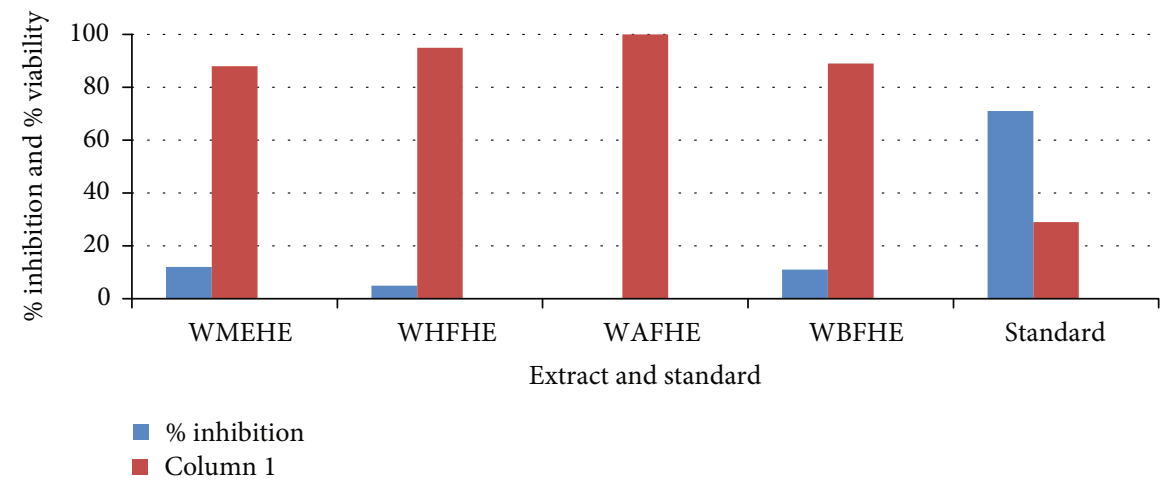

FIgURE 2: Anticancer assay (3T3) of the extract and fractions of the whole plant of Heliotropium europaeum.

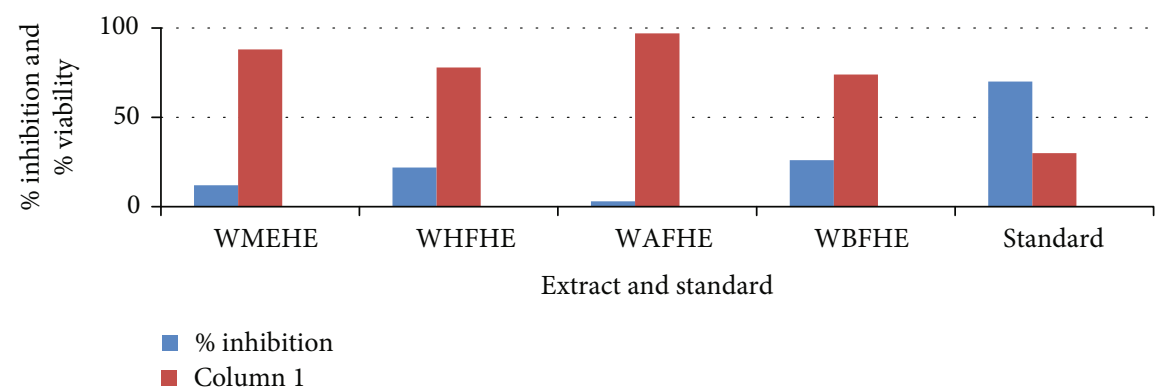

Figure 3: Anticancer assay (HeLa cell line) of the extract and fractions of the whole plant of Heliotropium europaeum.

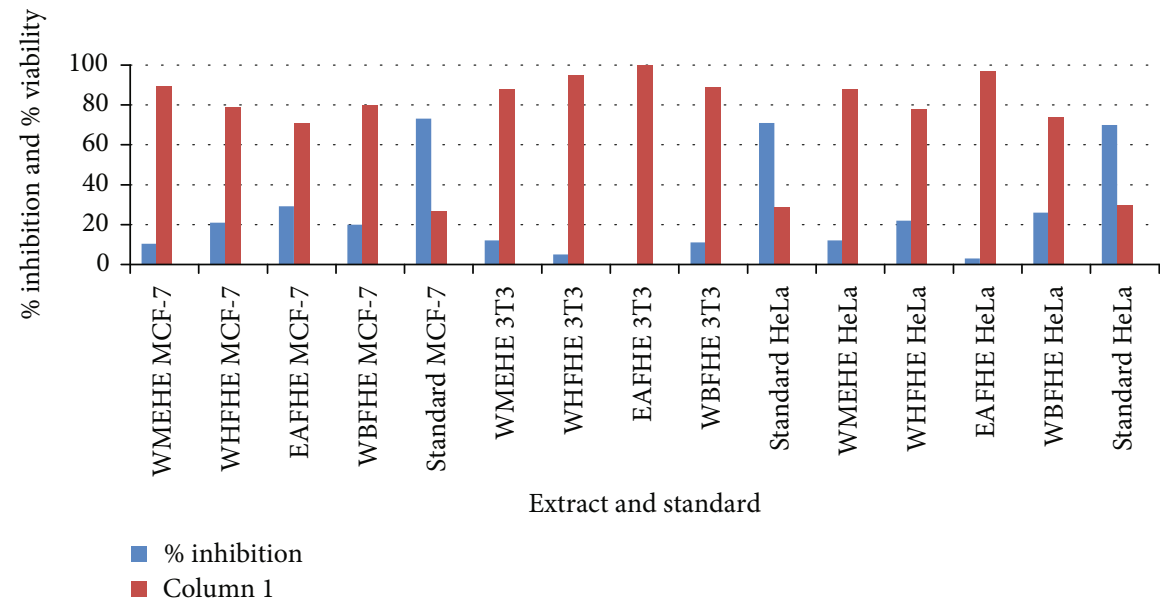

Figure 4: Anticancer assay (MCF-7, 3T3, and Hela cell lines) of the extract and fractions of the whole plant of Heliotropium europaeum.

(7) Whole-plant chloroform fraction of Heliotropium europaeum (WCFHE)

(8) Whole-plant tetrachloromethane fraction of Heliotropium europaeum (WTFHE)

The whole-plant butanol fraction of Heliotropium europaeum (WBFHE) showed anti-inflammatory activity on ROS having $\mathrm{IC}_{50} 14.7 \pm 2.5$ while the extract and other fractions of the whole plant of Heliotropium europaeum exhibited no anti-inflammatory activity. The antiinflammatory activity of the extract and fractions of the whole plant of Heliotropium europaeum is shown in Table 2.

None of the extract and fractions of the whole plant of Heliotropium europaeum exhibited anticancer (MCF-7, 3T3, and HeLa cell lines) activities. Anticancer activities of the extract and fractions of the whole plant of Heliotropium europaeum are shown in Tables 3-5 and Figures 1-4. 
TABLE 6: Brine shrimp lethality bioassay of the extract and fractions of the whole plant of Heliotropium europaeum.

\begin{tabular}{|c|c|c|c|c|c|c|c|c|}
\hline S. no & Extract and fractions & Dose $(\mu \mathrm{g} / \mathrm{ml})$ & No. of shrimps & No. of survivors & $\%$ mortality & LD50 $(\mu \mathrm{g} / \mathrm{ml})$ & Std. drug & $\mathrm{LD}_{50}(\mu \mathrm{g} / \mathrm{ml})$ \\
\hline & & 10 & 30 & 30 & $0 \%$ & & & \\
\hline \multirow[t]{3}{*}{1} & WMEHE & 100 & 30 & 30 & $0 \%$ & & Etoposide & 7.4625 \\
\hline & & 1000 & 30 & 30 & $0 \%$ & & & \\
\hline & & 10 & 30 & 30 & $0 \%$ & & & \\
\hline \multirow[t]{3}{*}{2} & WHFHE & 100 & 30 & 30 & $0 \%$ & & Etoposide & 7.4625 \\
\hline & & 1000 & 30 & 30 & $0 \%$ & & & \\
\hline & & 10 & 30 & 30 & $0 \%$ & & & \\
\hline \multirow[t]{3}{*}{3} & WAFHE & 100 & 30 & 30 & $0 \%$ & & Etoposide & 7.4625 \\
\hline & & 1000 & 30 & 28 & $6.66 \%$ & & & \\
\hline & & 10 & 30 & 30 & $0 \%$ & & & \\
\hline \multirow[t]{2}{*}{4} & WBFHE & 100 & 30 & 29 & $3.33 \%$ & & Etoposide & 7.4625 \\
\hline & & 1000 & 30 & 19 & $36.66 \%$ & & & \\
\hline
\end{tabular}

TABLE 7: FTIR analysis of the whole-plant methanol extract of Heliotropium europaeum (WMEHE).

\begin{tabular}{lcccccccc}
\hline S. no. & Peak & Height & Corr. height & Base $(H)$ & Base $(L)$ & Area & Corr. area & Interpretation \\
\hline 1 & 509.21 & 56.905 & 0.147 & 511.14 & 457.13 & 18.872 & 0.075 & S-S disulfide \\
2 & 567.07 & 56.1 & 0.103 & 576.72 & 563.21 & 4.82 & 0.008 & C-Br \\
3 & 1082.07 & 60.349 & 3.539 & 1132.21 & 891.11 & 85.528 & 0.029 & C-O stretch of esters \\
4 & 1143.79 & 58.889 & 0.029 & 1155.36 & 1134.14 & 8.188 & 0.472 & C-O stretch of ethers \\
5 & 1163.08 & 58.869 & 0.101 & 1195.87 & 1157.29 & 14.799 & 0.339 & C-H wag (-CH2X) \\
6 & 1236.37 & 59.02 & 1.042 & 1280.73 & 1197.79 & 31.687 & 0.021 & P-H bending of phosphine \\
7 & 1394.53 & 61.578 & 0.131 & 1408.04 & 1388.75 & 7.997 & 0.192 & S=O sulfate esters \\
8 & 1436.97 & 61792 & 1.586 & 1510.26 & 1425.4 & 32.271 & 0.035 & Ar C-C stretch \\
9 & 1629.85 & 60.249 & 0.435 & 1635.64 & 1512.19 & 44.756 & 0.005 & Ar CH=CHR aromatic alkenes \\
10 & 1722.43 & 59.069 & 0.196 & 1724.36 & 1691.57 & 12.183 & 0.569 & C=O stretch of esters \\
11 & 2162.2 & 28.864 & 0.359 & 2193.06 & 1977.04 & 30.999 & 17.363 & Si-H silane \\
12 & 2343.51 & 45.883 & 14.637 & 2405.23 & 2208.49 & 37.791 & 90.882 & P-H phosphine sharp \\
13 & 2933.73 & 61.877 & 13.199 & 3045.6 & 2407.16 & 173.618 & & C-H stretch of alkanes \\
14 & 3356.14 & 59.289 & 27.719 & 3786.27 & 3047.53 & 214.072 & & ArO-H H-bonded of phenols \\
\hline
\end{tabular}

TABLE 8: FTIR analysis of the whole-plant hexane fraction of Heliotropium europaeum (WHFHE).

\begin{tabular}{lcccccccc}
\hline S. no. & Peak & Height & Corr. height & Base $(H)$ & Base $(L)$ & Area & Corr. area & Interpretation \\
\hline 1 & 709.8 & 71.892 & 4.287 & 794.67 & 514.99 & 144.151 & 8.191 & C-H out of plane of aromatics \\
2 & 848.68 & 69.698 & 0.827 & 875.68 & 796.6 & 40.345 & 0.504 & C-H out of plane of aromatics \\
3 & 910.4 & 69.82 & 0.326 & 939.33 & 877.61 & 31.969 & 0.156 & N-H wag amines \\
4 & 1107.14 & 72.618 & 0.505 & 1136.07 & 941.26 & 106.771 & 1.709 & C-N stretch of amines \\
5 & 1176.58 & 72.667 & 0.338 & 1327.03 & 1138 & 105.055 & 0.476 & C-O stretch of esters \\
6 & 1332.81 & 71.496 & 0.004 & 1340.53 & 1328.95 & 6.308 & 0 & N-O sym stretch of nitro compound \\
7 & 1396.46 & 72.004 & 0.174 & 1415.75 & 1342.46 & 40.297 & 0.101 & S=O sulfate esters \\
8 & 1448.54 & 72.57 & 1.23 & 1502.55 & 1417.68 & 46.721 & 0.915 & Ar C-C stretch \\
9 & 1544.98 & 71.676 & 1.37 & 1595.13 & 1404.48 & 48.746 & 0.937 & N-O asym stretch of nitro compound \\
10 & 1735.93 & 72.649 & 15.406 & 1907.6 & 1597.06 & 131.605 & 17.518 & C=O stretch of esters \\
11 & 2872.01 & 68.436 & 1.523 & 2899.01 & 2401.38 & 200.732 & 10.737 & C-H stretch of alkanes \\
12 & 2958.8 & 69.969 & 2.214 & 3138.18 & 2900.94 & 118.397 & 2.981 & C-H stretch of alkanes \\
13 & 3307.92 & 67.218 & 0.013 & 3311.78 & 3140.11 & 82.598 & 0.112 & ArO-H H-bonded of phenols \\
14 & 3329.14 & 67.239 & 0.01 & 3336.85 & 3311.78 & 12.149 & 0.001 & N-H stretch of amines \\
\hline
\end{tabular}


TABLE 9: FTIR analysis of the whole-plant aqueous fraction of Heliotropium europaeum (WAFHE).

\begin{tabular}{lcccccccc}
\hline S. no. & Peak & Height & Corr. height & Base $(H)$ & Base $(L)$ & Area & Corr. area & Interpretation \\
\hline 1 & 503.42 & 58.347 & 0.299 & 507.28 & 464.84 & 15.692 & 0.115 & S-S disulfide \\
2 & 542 & 59.12 & 0.12 & 553.57 & 538.14 & 5.98 & 0.012 & C-Br stretch \\
3 & 1085.92 & 60.482 & 4.956 & 1193.94 & 914.26 & 104.059 & 7.441 & C-N stretch of amines \\
4 & 1236.37 & 58.967 & 0.869 & 1278.81 & 1195.87 & 31.726 & 0.395 & C-H wag $(-\mathrm{CH} 2 \mathrm{X})$ \\
5 & 1367.53 & 60.857 & 0.077 & 1369.46 & 1290.38 & 31.112 & 0.116 & S=O esters \\
6 & 1404.18 & 61.898 & 0.071 & 1406.11 & 1369.40 & 15.154 & 0.028 & S=O sulfate esters \\
7 & 1435.04 & 62.618 & 0.128 & 1438.9 & 1425.4 & 5.75 & 0.012 & Ar C-C stretch \\
8 & 1543.05 & 59.517 & 0.168 & 1546.91 & 1510.26 & 14.182 & 0.059 & N-O asym stretch of nitro compounds \\
9 & 1571.99 & 60.098 & 0.077 & 1573.91 & 1558.48 & 6.125 & 0.008 & N=O nitroso \\
10 & 1631.78 & 62.413 & 0.105 & 1633.71 & 1575.84 & 23.792 & 0.041 & NH2 in plane bend of amine \\
11 & 1643.35 & 62.75 & 0.205 & 1649.14 & 1635.64 & 5.774 & 0.021 & C=N \\
12 & 2954.95 & 56.255 & 3.937 & 3026.31 & 2403.3 & 169.441 & 7.483 & C-H stretch of alkanes \\
13 & 3300.2 & 58.334 & 0.054 & 3304.06 & 3028.24 & 100.312 & 0.428 & ArO-H H-bonded of phenols \\
14 & 3381.21 & 58.978 & 0.035 & 3385.07 & 3305.99 & 30.353 & 0.027 & N-H stretch of amines \\
\hline
\end{tabular}

TABLE 10: FTIR analysis of the whole-plant butanol fraction of Heliotropium europaeum (WBFHE).

\begin{tabular}{lcccccccc}
\hline S. no. & Peak & Height & Corr. height & Base $(H)$ & Base $(L)$ & Area & Corr. area & Interpretation \\
\hline 1 & 526.57 & 60.462 & 0.202 & 528.5 & 455.2 & 27.591 & 0.578 & S-S disulfide \\
2 & 557.43 & 60.525 & 0.205 & 565.14 & 549.71 & 6.213 & 0.02 & C-Br \\
3 & 787.03 & 57.485 & 0.066 & 792.74 & 771.53 & 7.873 & 0.008 & C-Cl \\
4 & 1093.64 & 72.754 & 7.211 & 1190.08 & 896.9 & 146.453 & 17.993 & C-O stretch of ethers \\
5 & 1236.37 & 72.97 & 2.73 & 1296.16 & 1192.01 & 56.711 & 2.085 & C-H wag $(-\mathrm{CH} 2 \mathrm{X})$ \\
6 & 1375.25 & 72.012 & 1.477 & 1409.96 & 1298.09 & 59.987 & 1.356 & $\mathrm{CH}$ and CH3 of alkanes \\
7 & 1440.83 & 72.733 & 4.684 & 1516.05 & 1417.86 & 48.245 & 3.253 & S=O sulfate esters \\
8 & 1627.92 & 68.05 & 0.069 & 1629.85 & 1614.42 & 7.612 & 0.012 & C=N \\
9 & 1722.43 & 71.371 & 15.773 & 1840.09 & 1681.93 & 54.691 & 8.927 & Monomer C=O of carboxylic acids \\
10 & 2058.05 & 23.659 & 0.013 & 2059.98 & 2011.76 & 5.615 & 0.008 & N=C in R-N=C=S \\
11 & 2945.3 & 72.963 & 18.244 & 3041.74 & 2407.16 & 207.79 & 34.031 & C-H stretch of alkanes \\
12 & 3367.71 & 69.56 & 36.829 & 3693.68 & 3043.67 & 260.725 & 125.447 & Dimer O-H of carboxylic acids \\
\hline
\end{tabular}

TABLE 11: FTIR analysis of the WEHE5 whole-plant ether fraction of Heliotropium europaeum (WEFHE).

\begin{tabular}{lcccccccc}
\hline S. no. & Peak & Height & Corr. height & Base $(H)$ & Base $(L)$ & Area & Corr. area & Interpretation \\
\hline 1 & 526.57 & 67.089 & 0.244 & 528.5 & 414.7 & 47.877 & 0.959 & S-S disulfide \\
2 & 542 & 67.422 & 0.24 & 545.85 & 530.42 & 7.488 & 0.033 & C-Br \\
3 & 837.11 & 64.225 & 6.395 & 894.97 & 804.32 & 37.173 & 3.73 & C-Cl \\
4 & 1056.99 & 85.296 & 15.749 & 1168.86 & 987.55 & 121.948 & 29.855 & P-H bending of phosphine \\
5 & 1228.66 & 69.684 & 2.584 & 1259.52 & 1170.79 & 43.885 & 1.595 & C-H wag (-CH2X) \\
6 & 1269.16 & 68.233 & 0.066 & 1280.73 & 1261.451282 .66 & 9.597 & 0.009 & C-O stretch of carboxylic acids \\
7 & 1394.53 & 76.531 & 2.519 & 1417.68 & 1282.66 & 77.545 & 3.229 & S=O sulfate esters \\
8 & 1452.4 & 80.038 & 12.112 & 1575.84 & 1419.61 & 70.087 & 7.949 & CH2 and CH3 of alkanes \\
9 & 1705.07 & 62.731 & 30.359 & 1832.38 & 1577.77 & 71.348 & 27.206 & Dimer C=O of carboxylic acids \\
10 & 2036.83 & 25.82 & 2.664 & 2129.41 & 1982.82 & 17.65 & 1.04 & N=C in R-N=C=S \\
11 & 2183.42 & 23.243 & 0.678 & 2216.21 & 2131.34 & 9.575 & 0.187 & Si-H silane \\
12 & 2341.58 & 40.615 & 13.598 & 2399.45 & 2249 & 25.344 & 5.458 & P-H phosphine sharp \\
13 & 2889.37 & 83.769 & 1.082 & 2899.01 & 2401.38 & 176.297 & 0.617 & C-H stretch of alkanes \\
14 & 2951.09 & 86.663 & 9.854 & 3035.96 & 2900.94 & 95.107 & 11.272 & C-H stretch of alkanes \\
15 & 3385.07 & 83.763 & 45.421 & 3728.4 & 3037.89 & 387.188 & 210.043 & Dimer OH of carboxylic acids \\
\hline
\end{tabular}


TABLE 12: FTIR analysis of the whole-plant dichloromethane fraction of Heliotropium europaeum (WDFHE).

\begin{tabular}{|c|c|c|c|c|c|c|c|c|}
\hline S. no. & Peak & Height & Corr. height & Base $(H)$ & Base $(L)$ & Area & Corr. area & Interpretation \\
\hline 3 & 509.21 & 66.099 & 0.243 & 518.85 & 501.49 & 8.128 & 0.026 & S-S disulfide \\
\hline 4 & 545.85 & 65.557 & 0.072 & 551.64 & 540.07 & 5.353 & 0.006 & $\mathrm{C}-\mathrm{Br}$ \\
\hline 5 & 677.01 & 64.418 & 0.489 & 700.16 & 644.22 & 24.94 & 0.179 & $=\mathrm{CH}$ out of plane of alkene \\
\hline 7 & 779.24 & 66.065 & 0.653 & 796.6 & 717.52 & 36.174 & 0.265 & $\mathrm{~N}-\mathrm{H}$ wag amines \\
\hline 8 & 831.32 & 66.341 & 1.118 & 896.9 & 798.53 & 45.718 & 0.919 & $\mathrm{C}-\mathrm{H}$ out of plane of aromatics \\
\hline 9 & 1022.27 & 70.209 & 1.238 & 1045.42 & 898.83 & 72.487 & 1.804 & $\mathrm{P}-\mathrm{H}$ bending of phosphine \\
\hline 10 & 1128.36 & 71.605 & 0.119 & 1134.14 & 1047.35 & 46.475 & 0.176 & C-N stretch of amines \\
\hline 11 & 1170.79 & 71.839 & 0.309 & 1211.3 & 1136.07 & 41.235 & 0.197 & $\mathrm{C}-\mathrm{O}$ stretch of esters \\
\hline 12 & 1255.66 & 71.674 & 0.417 & 1307.74 & 1213.23 & 51.476 & 0.325 & C-H wag (-CH2X) \\
\hline 13 & 1377.17 & 71.741 & 0.552 & 1411.89 & 1309.67 & 55.549 & 0.369 & $\mathrm{CH} 2$ and $\mathrm{CH} 3$ of alkanes \\
\hline 14 & 1448.54 & 71.855 & 2.008 & 1521.84 & 1421.54 & 52.27 & 1.535 & Ar C-C stretch of phenols \\
\hline 15 & 1597.06 & 86.317 & 0.075 & 1598.99 & 1523.76 & 36.514 & 0.088 & $\mathrm{NH} 2$ in plane bend \\
\hline 16 & 1612.49 & 68.717 & 0.066 & 1614.42 & 1598.99 & 7.742 & 0.006 & $\mathrm{C}=\mathrm{C}$ stretch of alkenes \\
\hline 17 & 1724.36 & 72.514 & 14.099 & 1890.24 & 1616.35 & 117.083 & 16.523 & $\mathrm{C}=\mathrm{O}$ stretch of esters \\
\hline 19 & 2343.51 & 59.216 & 9.459 & 2405.23 & 2038.76 & 99.242 & 5.54 & P-H phosphine sharp \\
\hline 20 & 2573.04 & 75.36 & 2.07 & 2654.05 & 2407.16 & 88.15 & 3.802 & S-H sharp of thiols \\
\hline 21 & 2958.8 & 69.273 & 8.105 & 3061.03 & 2655.98 & 177.621 & 17.639 & $\mathrm{C}-\mathrm{H}$ stretch of alkanes \\
\hline 22 & 3113.11 & 63.003 & 0.016 & 3115.04 & 3062.96 & 22.368 & 0.011 & $=\mathrm{C}-\mathrm{H}$ stretch of alkenes \\
\hline 23 & 3307.92 & 66.138 & 0.071 & 331.78 & 3115.04 & 89.183 & 0.536 & ArO-H H-bonded of phenols \\
\hline 24 & 3327.21 & 66.29 & 0.02 & 3329.14 & 3313.71 & 7.269 & 0.001 & $\mathrm{~N}-\mathrm{H}$ stretch of amines \\
\hline 28 & 3402.43 & 66.579 & 0.045 & 3415.93 & 3394.72 & 10.093 & 0.008 & $\mathrm{~N}-\mathrm{H}$ stretch of amines \\
\hline
\end{tabular}

TABLE 13: FTIR analysis of the whole-plant chloroform fraction of Heliotropium europaeum (WCFHE).

\begin{tabular}{|c|c|c|c|c|c|c|c|c|}
\hline S. no. & Peak & Height & Corr. height & Base $(H)$ & Base $(L)$ & Area & Corr. area & Interpretation \\
\hline 1 & 524.64 & 35.914 & 3.296 & 565.14 & 405.05 & 27.586 & 1.549 & S-S disulfide \\
\hline 2 & 611.43 & 34.252 & 0.048 & 617.22 & 567.07 & 9.095 & 0.017 & $\mathrm{C}-\mathrm{Br}$ \\
\hline 3 & 825.53 & 39.54 & 0.956 & 846.75 & 727.16 & 24.686 & 0.538 & $\mathrm{~N}-\mathrm{H}$ wag amines \\
\hline 4 & 1004.91 & 53.907 & 5.508 & 1037.7 & 887.26 & 42.198 & 3.138 & $\mathrm{P}-\mathrm{H}$ bending of phosphine \\
\hline 5 & 1101.35 & 61.8 & 3.37 & 1124.5 & 1039.63 & 32.25 & 1.729 & C-N stretch of amines \\
\hline 6 & 1145.72 & 61.54 & 1.113 & 1192.01 & 1126.43 & 26.692 & 0.607 & C-O stretch of esters \\
\hline 7 & 1236.37 & 61.804 & 5.301 & 1305.81 & 1193.94 & 42.658 & 2.845 & C-H wag (-CH2X) \\
\hline 8 & 1363.67 & 55.831 & 5.527 & 1417.68 & 1307.74 & 36.288 & 2.751 & $\mathrm{C}-\mathrm{H}$ rock of alkanes \\
\hline 9 & 1450.47 & 51.6 & 7.497 & 1535.34 & 1419.61 & 29.295 & 2.774 & $\mathrm{CH}_{2}$ and $\mathrm{CH}_{3}$ of alkanes \\
\hline 10 & 1610.56 & 43.11 & 5.439 & 1656.85 & 1537.27 & 26.19 & 2.202 & $\mathrm{NH}_{2}$ in plane bend of amines \\
\hline 11 & 1722.29 & 54.706 & 18.628 & 2029.11 & 1658.78 & 56.075 & 7.445 & $\mathrm{C}=\mathrm{O}$ stretch of esters \\
\hline 12 & 2073.48 & 18.552 & 0.007 & 2079.26 & 2054.19 & 2.234 & 0.001 & $\mathrm{~N}=\mathrm{C}$ in $\mathrm{R}-\mathrm{N}=\mathrm{C}=\mathrm{S}$ \\
\hline 13 & 2341.58 & 32.536 & 13.367 & 2405.23 & 2102.41 & 32.959 & 5.348 & P-H phosphine sharp \\
\hline 14 & 2563.4 & 20.744 & 0.021 & 2571.11 & 2515.18 & 5.636 & 0.006 & S-H sharp of thiols \\
\hline 15 & 2582.68 & 20.744 & 0.025 & 2611.62 & 2573.04 & 3.89 & 0.003 & $(\mathrm{O}=)$ PO-H phosphoric acids \\
\hline 16 & 2951.09 & 48.718 & 22.524 & 3039.81 & 2613.55 & 71.029 & 20.094 & C-H stretch of alkanes \\
\hline 17 & 3387 & 37.471 & 20.375 & 3685.97 & 3041.74 & 99.785 & 42.816 & $\mathrm{~N}-\mathrm{H}$ stretch of amines \\
\hline
\end{tabular}

The whole-plant aqueous fraction of Heliotropium europaeum (WAFHE) and whole-plant butanol fraction of Heliotropium europaeum (WBFHE) showed lethality at high concentration while at low concentration, no toxicity was shown. The whole-plant methanolic extract of Heliotropium europaeum (WMEHE) and whole-plant n-hexane fraction of Heliotropium europaeum (WHFHE) exhibited no toxicity. The results of the brine shrimp lethality assay of the extract and fractions of the whole plant of Heliotropium europaeum are shown in Table 6. 
TABLE 14: FTIR analysis of the whole-plant tetrachloromethane fraction of Heliotropium europaeum (WTFHE).

\begin{tabular}{lcccccccc}
\hline S. no. & Peak & Height & Corr. height & Base $(H)$ & Base $(L)$ & Area & Corr. area & Interpretation \\
\hline 1 & 516.92 & 21.117 & 0.151 & 526.57 & 513.07 & 1.384 & 0.006 & S-S disulfide \\
2 & 794.67 & 16.108 & 0.01 & 796.6 & 781.17 & 1.175 & 0.001 & C-H out of plane of aromatics \\
3 & 800.46 & 16.113 & 0.045 & 958.62 & 796.6 & 11.715 & 0.077 & C-H out of plane of aromatics \\
4 & 1157.29 & 18.074 & 2.67 & 1271.09 & 960.55 & 24.623 & 2.378 & C-O stretch of esters \\
5 & 1365.6 & 14.92 & 0.202 & 1369.46 & 1350.17 & 1.335 & 0.011 & S=O esters \\
6 & 1483.26 & 15.627 & 0.503 & 1490.97 & 1473.62 & 1.263 & 0.026 & Ar C-C stretch of aromatics \\
7 & 1517.98 & 16.033 & 1.015 & 1548.84 & 1510.26 & 2.791 & 0.148 & N-O asym stretch of nitro compounds \\
8 & 1616.35 & 12.206 & 0.149 & 1618.28 & 1598.99 & 1.046 & 0.016 & C=N \\
9 & 1716.65 & 15.575 & 0.436 & 1722.43 & 1703.14 & 1.383 & 0.024 & C=O of carboxylic acids \\
10 & 1730.15 & 15.697 & 0.748 & 1799.59 & 1724.36 & 4.615 & 0.069 & C=O stretch of esters \\
11 & 2239.36 & 8.703 & 0.111 & 2249 & 2214.28 & 1.358 & 0.008 & Si-H silane \\
12 & 2929.87 & 13.999 & 7.508 & 3053.32 & 2725.42 & 13.854 & 4.244 & C-H stretch of alkanes \\
13 & 3078.39 & 6.297 & 0.044 & 3136.25 & 3072.6 & 1.761 & 0.01 & Ar-H stretch of aromatics \\
14 & 3188.33 & 6.016 & 0.004 & 3190.26 & 3153.61 & 0.981 & 0 & Dimer O-H of carboxylic acids \\
\hline
\end{tabular}

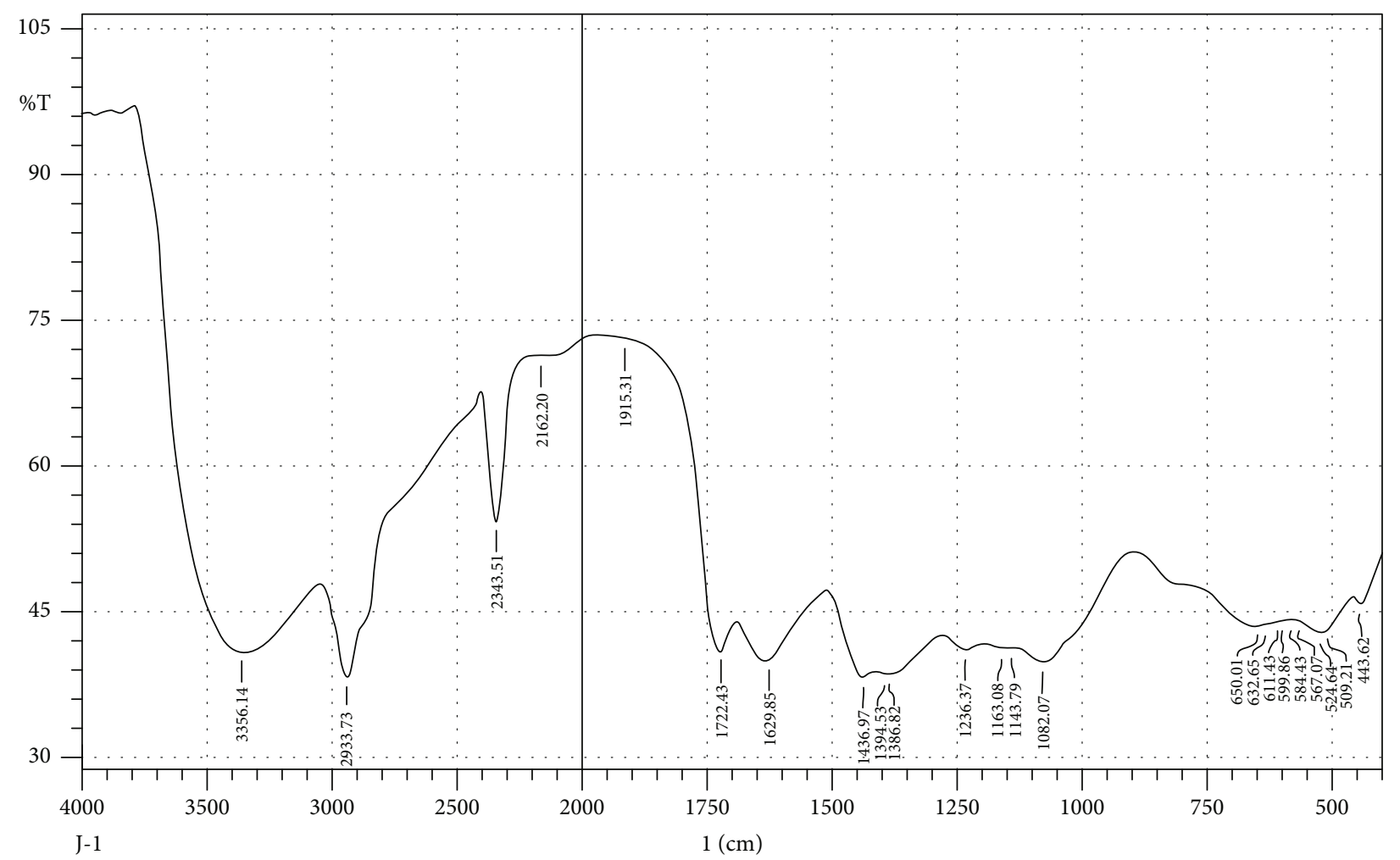

FIGURE 5: FTIR spectrum analysis of the whole-plant methanol extract of Heliotropium europaeum (WMEHE).

FTIR interpretation of the extract and fractions of Heliotropium europaeum showed the functional groups for the aromatic compounds, phenols, carboxylic acids, esters, alkanes, alkenes, alcohols, alkyl halides, sulfate esters, phosphines, silanes, nitriles, thiols, amines, phosphoric acids, and nitro compounds. FTIR analysis of the extract and fractions of the whole plant of Heliotropium europaeum is shown in Tables 7-14. FTIR analysis of the extract and fractions of the whole plant of Heliotropium europaeum is shown in Figures 5-12.

\section{Conclusion}

In this research study, the whole-plant butanol fraction of Heliotropium europaeum (WBFHE) showed antiinflammatory activity on $\mathrm{ROS}$ having $\mathrm{IC}_{50} \quad 14.7 \pm 2.5$ while the extract and other fractions of the whole plant of Heliotropium europaeum exhibited no anti-inflammatory activity. None of the extract and fractions of the whole plant of Heliotropium europaeum exhibited anticancer (MCF-7, 3T3, and HeLa cell lines) activities. The whole-plant aqueous 


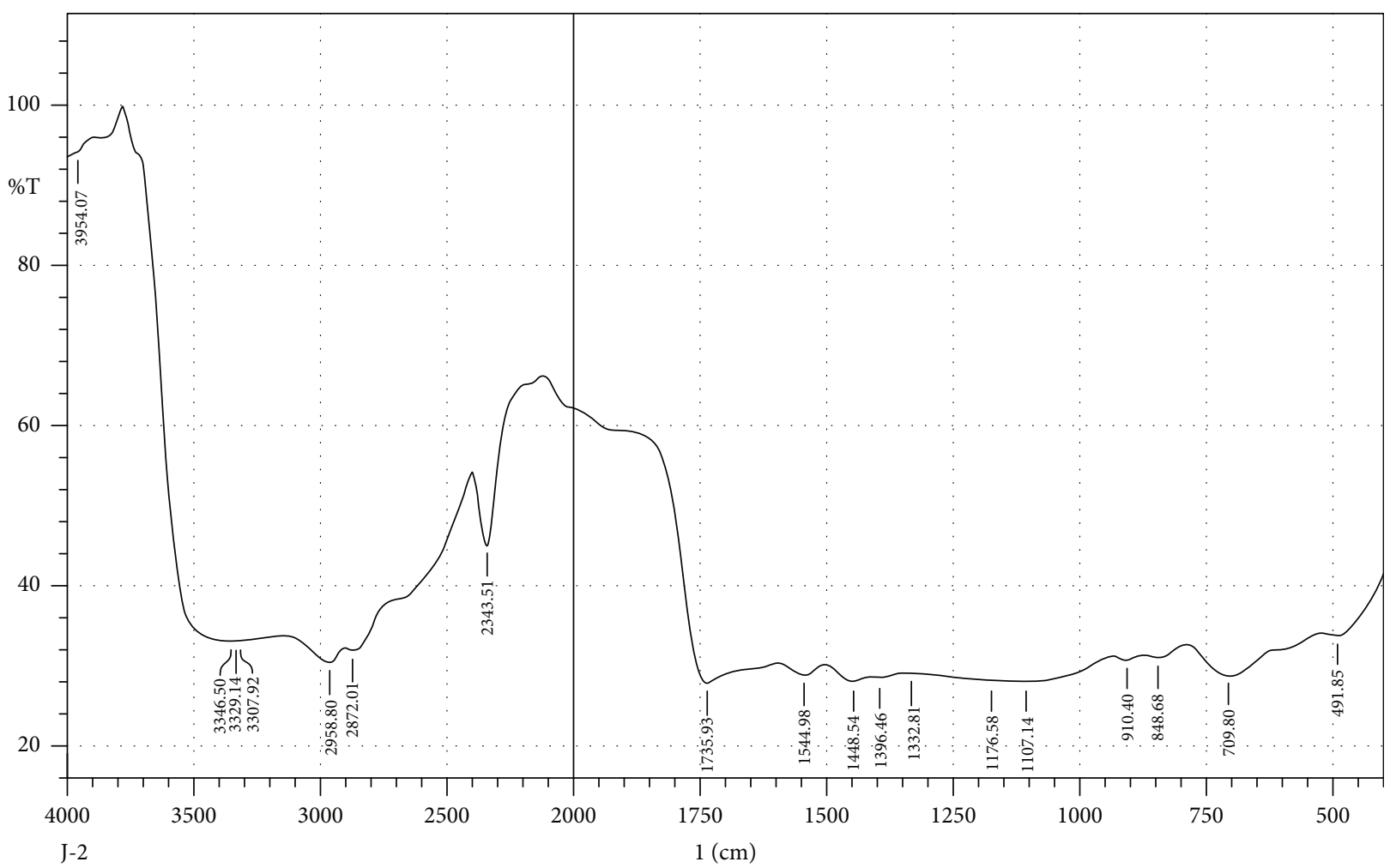

FIGURE 6: FTIR spectrum analysis of the whole-plant hexane fraction of Heliotropium europaeum (WHFHE).

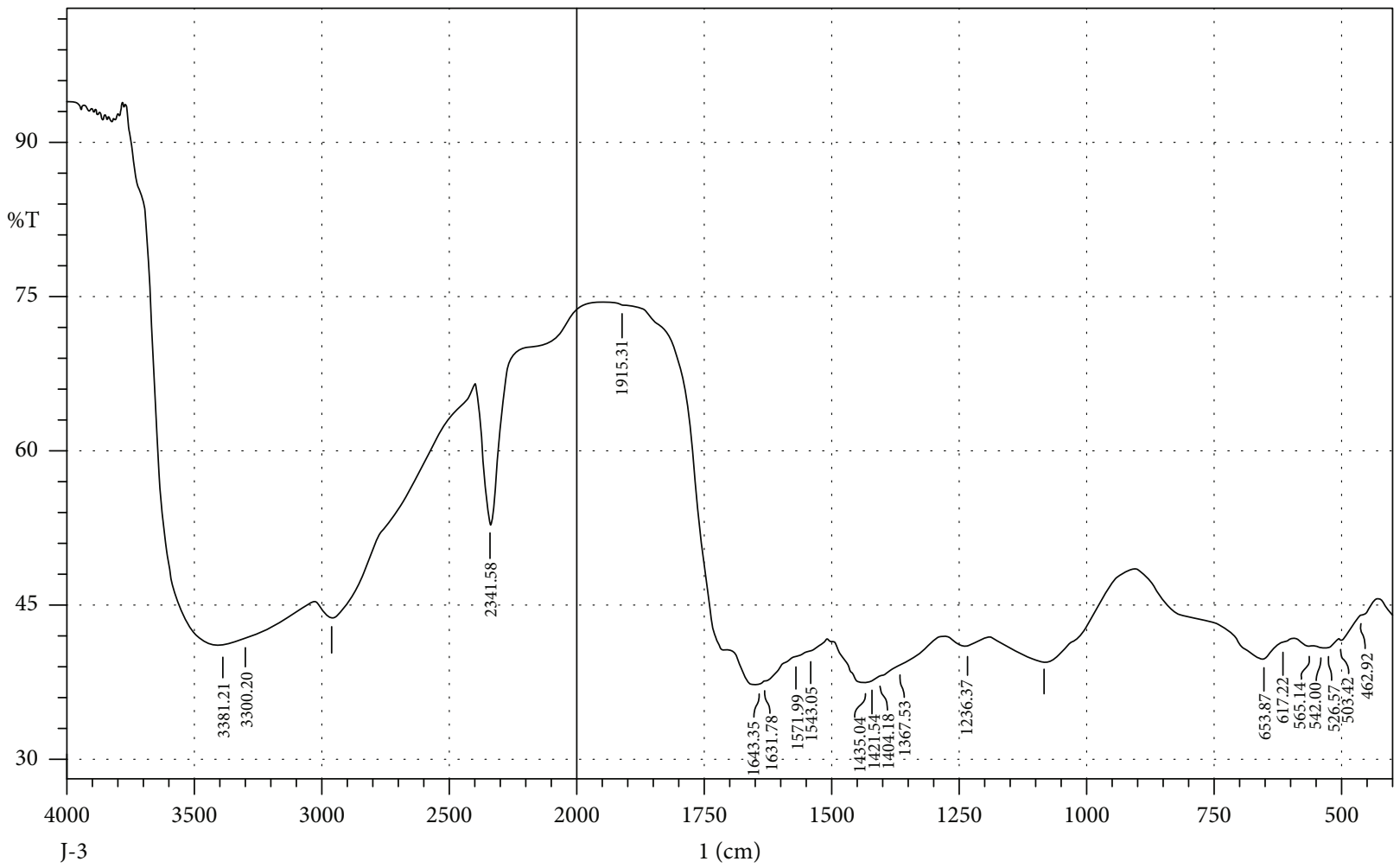

FIGURE 7: FTIR spectrum analysis of the whole-plant aqueous fraction of Heliotropium europaeum (WAFHE). 


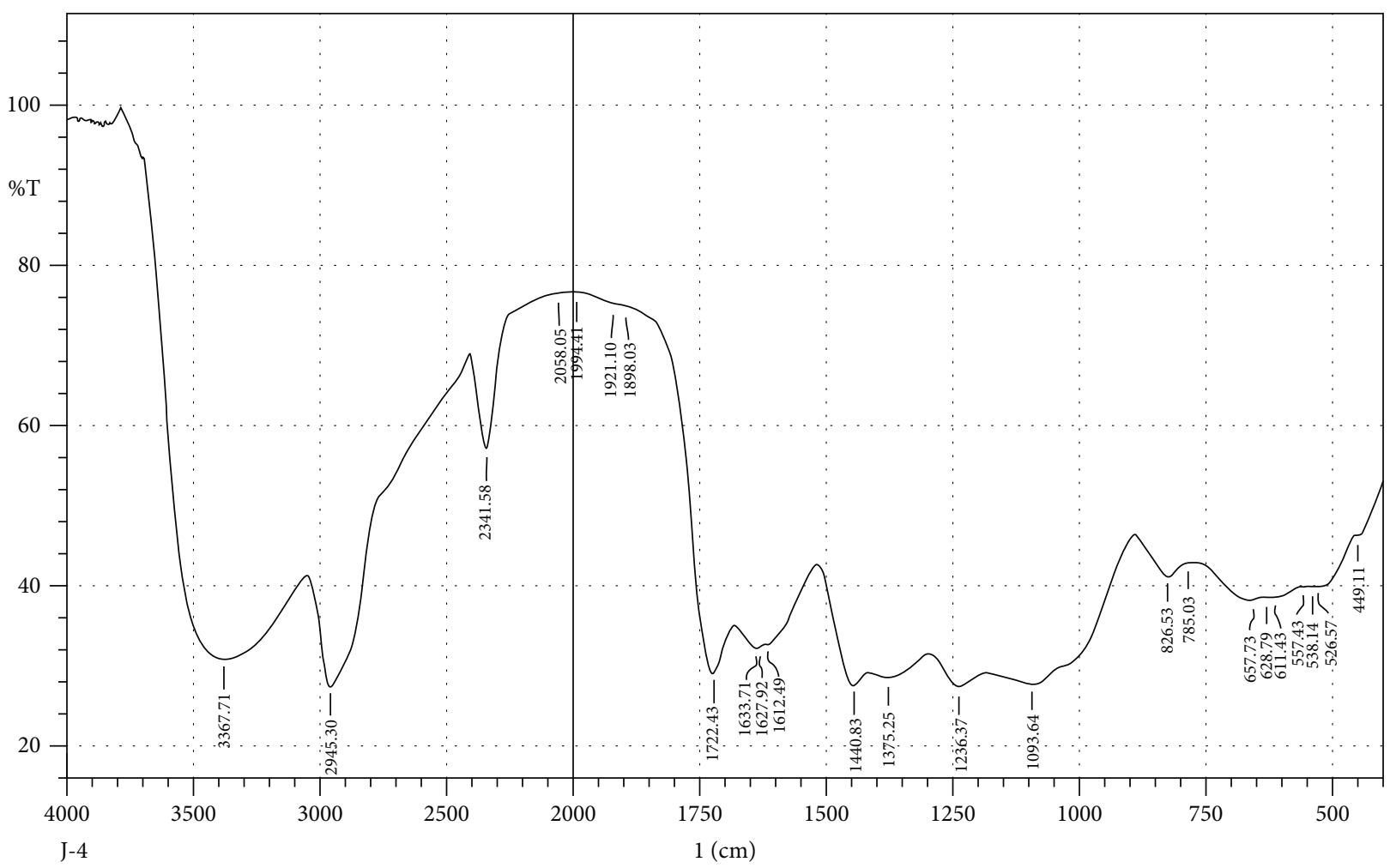

FIGURE 8: FTIR spectrum analysis of the whole-plant butanol fraction of Heliotropium europaeum (WBFHE).

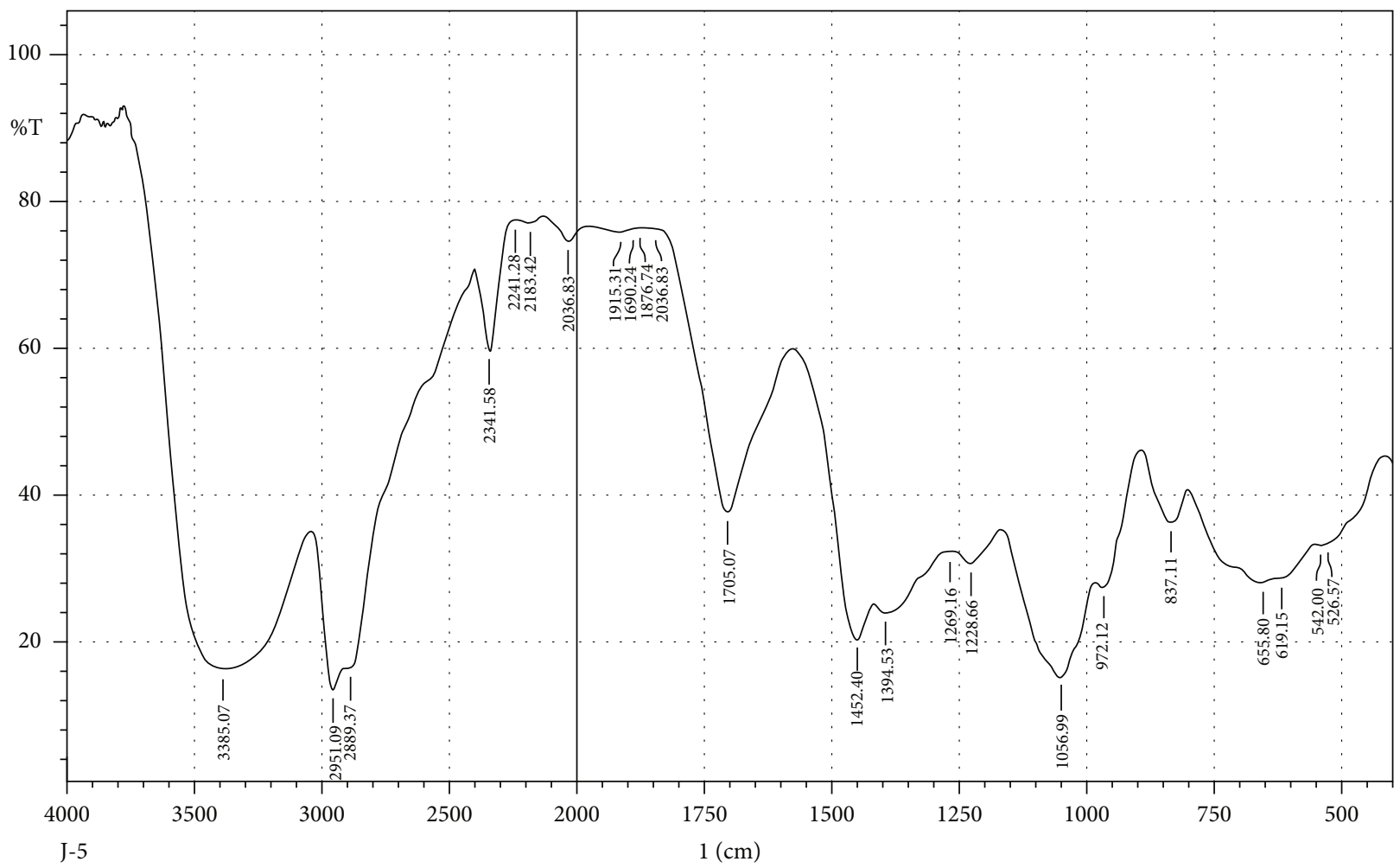

FIGURE 9: FTIR spectrum analysis of the whole-plant ether fraction of Heliotropium europaeum (WEFHE). 


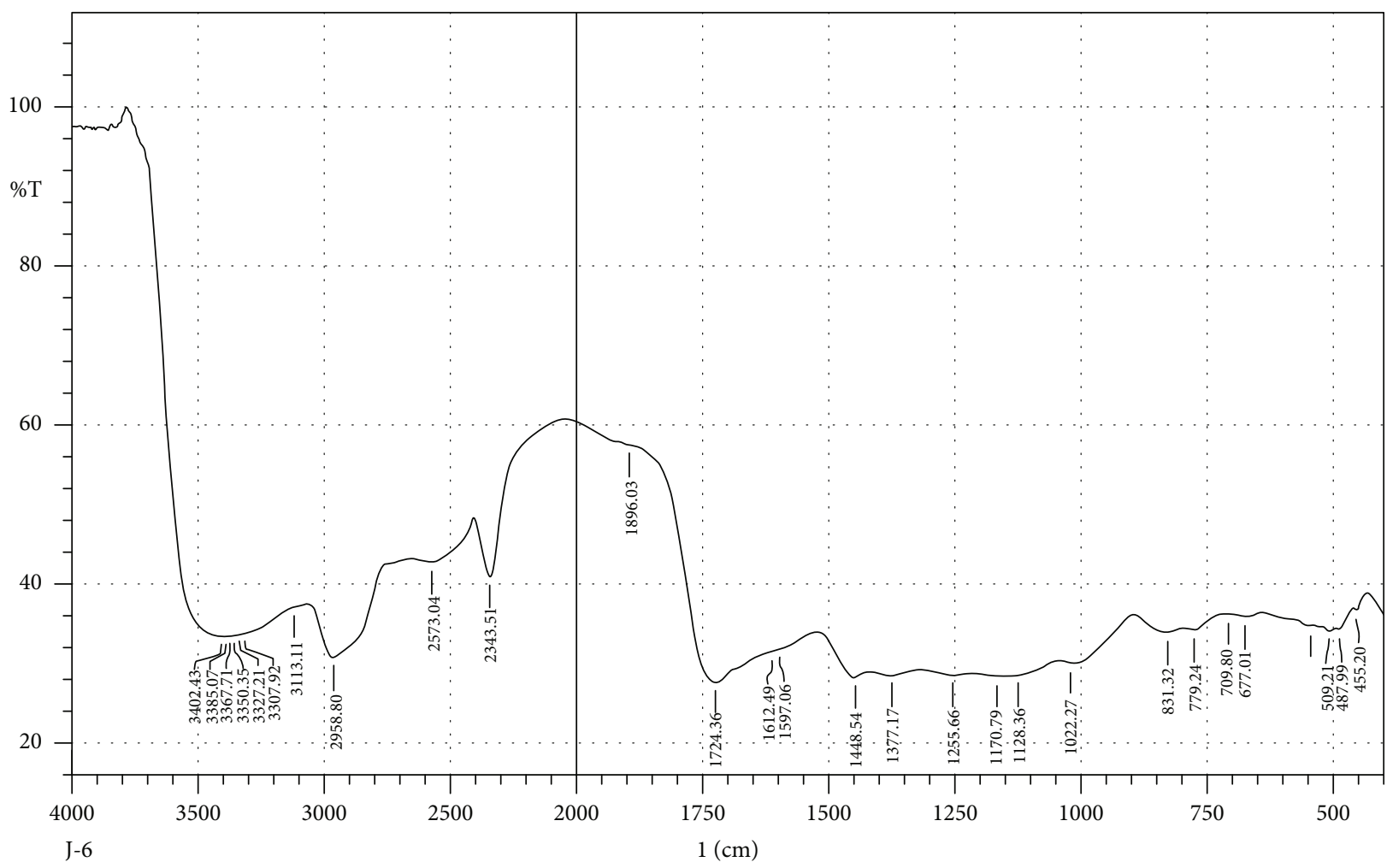

FIGURE 10: FTIR spectrum analysis of the whole-plant dichloromethane fraction of Heliotropium europaeum (WDFHE).

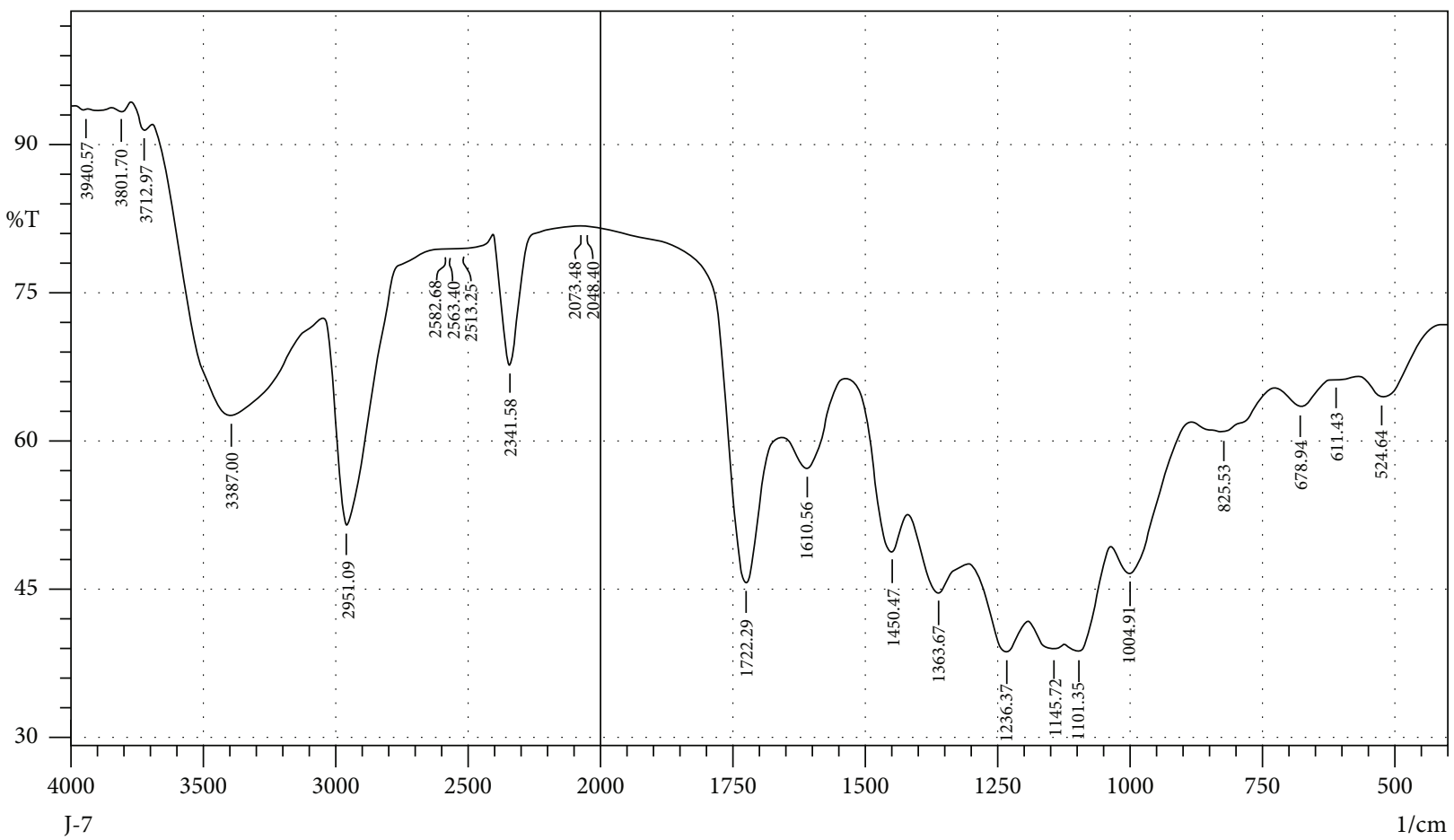

FIGURE 11: FTIR spectrum analysis of the whole-plant chloroform fraction of Heliotropium europaeum (WCFHE). 


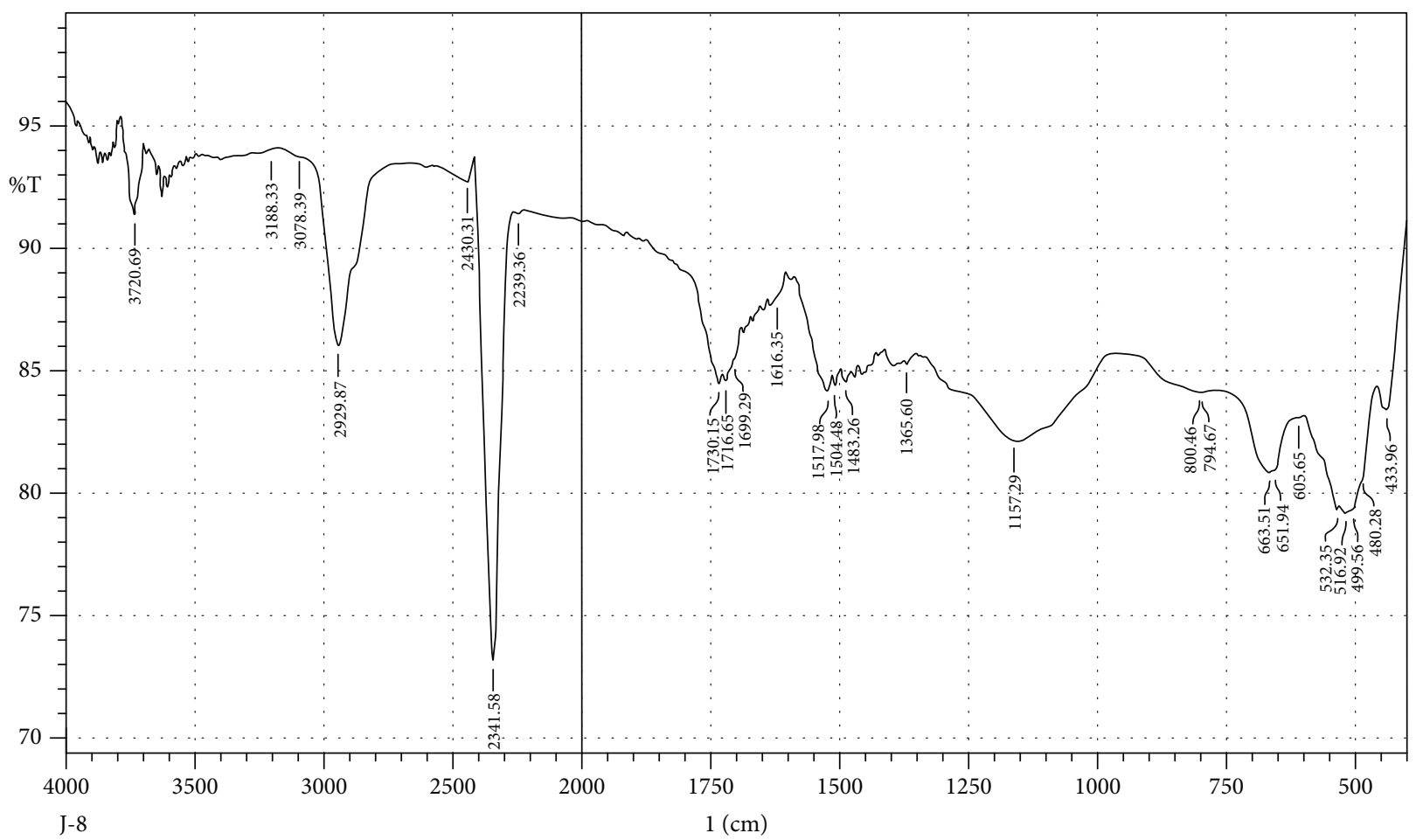

FIGURE 12: FTIR spectrum analysis of the whole-plant tetrachloromethane fraction of Heliotropium europaeum (WTFHE).

fraction of Heliotropium europaeum (WAFHE) and wholeplant butanol fraction of Heliotropium europaeum (WBFHE) showed lethality at high concentration while at low concentration, no toxicity was shown. The whole-plant methanolic extract of Heliotropium europaeum (WMEHE) and whole-plant n-hexane fraction of Heliotropium europaeum (WHFHE) exhibited no toxicity. FTIR interpretation showed the functional groups for the aromatic compounds, phenols, carboxylic acids, esters, alkanes, alkenes, alcohols, alkyl halides, sulfate esters, phosphines, silanes, nitriles, thiols, amines, phosphoric acids, and nitro compounds.

\section{Data Availability}

The data used to support the findings of this study are available from the corresponding author upon request.

\section{Conflicts of Interest}

The authors declare that there is no conflict of interests.

\section{Acknowledgments}

The authors are thankful to Hussain Ebrahim Jamal (HEJ), Research Institute of Chemistry, University of Karachi, Karachi, Pakistan, for providing biological activities and the Institute of Biochemistry, University of Balochistan, Quetta, Pakistan, for providing lab facilities for extraction and fractionation and FTIR analysis.

\section{References}

[1] S. Rajendran, A. Khan, M. Murphy, and D. O'Hanlon, "The diagnosis and treatment of a symptomatic mesenteric cyst," International Journal of Pharmaceutical Sciences and Research, vol. 2014, 2014.

[2] H. H. EL-Kamali and M. Y. EL-Amir, "Antibacterial activity and phytochemical screening of ethanolic extracts obtained from selected Sudanese medicinal plants," Current Research Journal of Biological Sciences, vol. 2, no. 2, pp. 143-146, 2010.

[3] P. Lalitha, K. A. Arathi, K. Shubashini, S. H. Sripathi, and P. Jayanthi, "Antimicrobial activity and phytochemical screening of an ornamental foliage plant, Pothos aurea (Linden ex Andre)," International Journal of Chem, vol. 1, no. 2, pp. 63-71, 2010.

[4] H. Hussain, A. Badawy, A. Elshazly et al., "Chemical constituents and antimicrobial activity of Salix subserrata," Records of Natural Products, vol. 5, no. 2, pp. 133-137, 2011.

[5] B. Mahesh and S. Satish, "Antimicrobial activity of some important medicinal plant against plant and human pathogens," World Journal of Agricultural Sciences, vol. 4, no. 5, pp. 839-843, 2008.

[6] N. Diane, H. H. Hilger, and M. G. Otischling, "Transfer cells in the seeds of Boraginales," Botanical Journal of the Linnean Society, vol. 140, no. 2, pp. 155-164, 2002.

[7] H. Riedl and H. Boraginaceae, In: flora des Iranischen hochlandes und der unrahmenden gebirge, R. H. Rechinger, Ed., Akad.Druk.Verlag., Graz, 1967.

[8] S. L. Everist, Poisonous plants of Australia, Angus \& Robertson Publication, Sydney, Australia, 1974.

[9] R. A. Mckenzie, Principles of animal health: introduction to veterinary toxicology for students of agricultural sciences, Academic Press, 2001. 
[10] D. A. Miller, "Allelopathy in forage crop systems," Agronomy Journal, vol. 88, no. 6, pp. 854-859, 1996.

[11] A. F. M. Rizk, The pyrrolizidine alkaloids: plant sources and properties in naturally occurring pyrrolizidine alkaloids, A.-F. M. Rizk, Ed., CRC Press, Inc., Boca Raton, 1991.

[12] J. Bakht, S. Khan, and M. Shafi, "Antimicrobial potentials of fresh Allium cepa against gram negative bacteria and fungi," Pakistan Journal of Botany, vol. 45, pp. 1-6, 2013.

[13] J. K. Achakzai, M. Anwar Panezai, M. A. Kakar et al., "In vitro anticancer MCF-7, anti-inflammatory, and brine shrimp lethality assay (BSLA) and GC-MS analysis of whole plant butanol fraction of Rheum ribes (WBFRR)," BioMed Research International, vol. 2019, Article ID 3264846, 8 pages, 2019.

[14] S. L. Helfand, J. Werkmeister, and J. C. Roder, "Chemiluminescence response of human natural killer cells. I. The relationship between target cell binding, chemiluminescence, and cytolysis," The Journal of Experimental Medicine, vol. 156, no. 2, pp. 492-505, 1982.

[15] D. A. Scudiero, R. H. Shoemaker, K. D. Paull et al., "Evaluation of a soluble tetrazolium/formazan assay for cell growth and drug sensitivity in culture using human and other tumor cell lines," Cancer Research, vol. 48, no. 17, pp. 4827-4833, 1988.

[16] T. M. de Almeida Alves, A. F. Silva, M. Brandão et al., "Biological screening of Brazilian medicinal plants," Memórias do Instituto Oswaldo Cruz, vol. 95, no. 3, pp. 367-373, 2000.

[17] P. G. Kareru, J. M. Keriko, A. N. Gachanja, and G. M. Kenji, "Direct detection of triterpenoid saponins, in medicinal plants," African Journal of Traditional, Complementary, and Alternative Medicines, vol. 5, pp. 56-60, 2008. 